\title{
LA DISCIPLINA COMO HÁBITO. Cacicazgo y alienación en la UNIVERSIDAD AUTÓNOMA del ESTADO de HIDALGO
}

\author{
David LAGUNAS \\ Universidad de Sevilla (España) \\ dlagunas@us.es
}

\begin{abstract}
DISCIPLINE AS A HABIT: Cacicazgo and alienation in the UNIVERSIDAD AUTÓNOMA del ESTADO de HIDALGO
\end{abstract}

Resumen: El caciquismo y el autoritarismo encuentran espacios de articulación en la transición hacia la democracia en México. Las formas de dominación del sistema de camarillas, característico del viejo régimen del PRI, convergen con efectos sorprendentes en el seno de la Universidad Autónoma del Estado de Hidalgo.

Abstract: The caciquism and authoritarianism find spaces of articulation in the transition to the democracy in Mexico. The forms of domination of the camarillas system, characteristic of the old PRI regime, converge with surprising effects in the Autonomous University of Hidalgo State.

Palabras clave: Universidad, Caciquismo, Dominación, Campo, Red University, Caciquism, Domination, Field, Network 


\section{Introducción}

Las relaciones patrón-cliente constituyen un tipo de economías morales basadas en los afectos, la lealtad y el paternalismo, una suerte de cultura íntima (Lomnitz (1996). Estas lógicas afectivas, lejos de desaparecer a medida que la democracia se consolida en el mundo, se adaptan a las transformaciones del capitalismo neoliberal. Ello puede indicarnos que no existe por definición incompatibilidad entre el clientelismo, por un lado, y la lógica liberal y/o el sistema democrático, por otro. El análisis del clientelismo y el caciquismo en las sociedades urbano-industriales no ha generado una abundante literatura científica y en las universidades el tema es ignorado, más allá de la denuncia en los medios de comunicación.

En el texto que desarrollo a continuación el foco de atención se traslada hacia una unidad de observación concreta, el Instituto de Ciencias Sociales y Humanidades (ICSHu) de la Universidad Autónoma del Estado de Hidalgo (UAEH), en la cual he desarrollado la etnografía entre 2005 y 2010. El tópico que discutimos son las formas clientelares de poder, alienación y control que ejerce la "red universidad" y en específico el grupúsculo político denominado Grupo Universidad que actualmente controla la UAEH ${ }^{1}$. Una razón esencial para haber escogido el ICSHu como unidad de observación es que este instituto desarrolla un tipo de investigación que tiene mayores oportunidades de conectarse con los intereses políticos del grupo caciquil en el poder, un aspecto central de mi trabajo. El ICSHu es un espacio de reclutamiento, no exclusivo al igual que la universidad, para apoyar al líder caciquil $^{2}$ y sus candidatos en sus funciones y campañas políticas. El ICSHu cuenta con la carrera de Derecho, la cual tuvo una implicación directa en la génesis del grupo caciquil ya que muchos de sus integrantes, incluyendo al propio líder, se formaron en esa carrera.

La auto-etnografía me brinda la posibilidad de la auto-reflexión y una metodología más pertinente respecto a mi objeto (ver Reed-Danahay, 2001). Por un lado, posibilita estudiar a mi propio "grupo", la red universidad; por otro, desarrollar un análisis de mis experiencias, privilegiando el rigor científico sobre la polémica, sin por ello perder de vista su importancia política. Esto último rebasa los fines puramente comprensivos de la ciencia, asumiendo plenamente su imperativo analítico, y tiene un componente irreductiblemente crítico y práctico. El análisis con crítica social y la crítica con radicalidad analítica se consolidan mutuamente, siendo vanos y paradójicos el uno sin el otro. No ha sido hasta haberme desvinculado de la UAEH que he podido estar en condición de desarrollar un análisis independiente que no resulte cautivo de las rivalidades internas y del resentir inmediato de situaciones vividas, ni expuesto a repercusiones represivas en condiciones demasiado adversas para lograr rebatirlas. Aún así, tal análisis tiene una vocación práctica que sólo puede nacer de una comprensión total y no parcial de las lógicas y relaciones de fuerza internas a la institución, si bien sólo pueda tener consecuencias desde posicionamientos internos que la integren.

Me ha interesado indagar sobre la institución universitaria y las relaciones humanas de mi ámbito de trabajo a partir de la inquietud revelada por Foucault (1997) acerca de las verdades que se presentan como deseables y las certidumbres que imponen, así como las relaciones y tratos generados a partir de las tramas discursivas, las cosas que pasan y nos pasan en nuestros espacios de trabajo cotidianos y que componen la disciplina como hábito (Foucault, 1986).

La tentativa de comprensión de la institución universitaria toma en consideración los aportes de Thompson (1994) y su crítica de la racionalidad formal de las organizaciones,

1 Fui profesor-investigador de la UAEH entre 2000 y 2010. De 2006 a 2008 ocupé el cargo de Jefe de Área Académica.

2 Gerardo Sosa Castelán. De aquí en adelante lo mencionaremos como "el líder" ya que este término posee una potencia explicativa y descriptiva que lo hace ubicuo. Con ello pretendemos anteponer el rigor en la definición de conceptos, a la manera de Bourdieu. 
planteando que existen diversas racionalidades formales que los agentes llevan consigo. No obstante, el conflicto de racionalidades al interior de las organizaciones se comprende mejor desde el concepto de "legitimidad" weberiano, más recompensante para nuestros intereses que el de "racionalidades". Weber (1984) explica que a través de los mecanismos de legitimación los individuos interiorizan un conjunto de normas y conductas a causa de las limitaciones que encuentran al desempeño de su libertad de acción. El consenso creado puede descansar en motivos muy diversos: desde la habituación inconsciente hasta lo que son consideraciones puramente racionales con arreglo a fines. Para Weber un determinado mínimo de voluntad de sumisión, de interés (externo o interno) en obedecer, es esencial en toda relación auténtica y legítima de autoridad.

El trabajo pionero de Lomnitz (1995) resulta inspirador para el análisis del caciquismo en México al igual que "el nuevo caciquismo" que describe Panster (2008:5) en relación a la Benemérita Universidad Autónoma de Puebla. No obstante, el caso de la UAEH aporta elementos de análisis a la sensación de alienación en el ámbito universitario, la cual se hace extraña pero debe entenderse desde la crítica más popular de la antropología y de una sociología conectadas con aquello que la gente común y corriente no entiende de la racionalidad interna de las instituciones, sus modelos racionales propios, su funcionamiento interno y que constituye su queja.

Desde la perspectiva sociológica, el concepto de campo social tal como lo desarrolló Bourdieu (1984a; 1992) resulta muy pertinente. El campo se define como una red de relaciones entre posiciones objetivas de agentes e instituciones, así como un espacio de lucha entre esos agentes e instituciones por la posesión de un capital específico y de los beneficios atribuidos a la posesión de ese capital. En torno a este concepto se desarrollará la reflexión a continuación.

\section{EI ICSHu desde la perspectiva de campo social}

En la sociedad hidalguense y dentro de los pocos textos críticos existentes sobre el cacicazgo de la UAEH (Herrera Cabañas, 1995; Rivera Flores, 2004), la forma tradicional de concebirlo consiste en contemplar el poder externo de un cacique que controla la institución a través de una camarilla interna leal a su persona. Las formulaciones periodísticas de una opinión crítica respecto a la $\mathrm{UAEH}^{3}$ acaban diluyéndose siendo acusadas por parte de sus destinatarios de haber insultado falsamente. Estos trabajos señalan que el Grupo Universidad define un grupo político que puso a una institución de educación superior al servicio de los intereses del líder y de sus seguidores es un planteamiento muy limitado para responder a preguntas cruciales en torno a las formas de inserción de un poder propiamente político en un contexto universitario y a las condiciones de su reproducción dentro de ese contexto.

La personalidad del líder no constituye ninguna explicación sociológica al tipo de dominación que su figura ejerce en la UAEH; su carácter excepcional es tan sólo una ilusión creada por el dispositivo de poder que requiere de la figura de ese líder. Por un lado, existe una interdependencia entre el capital político acumulado por él, a través y más allá de la universidad, y el propio manejo interno de sus seguidores. El líder no tiene en el campo político hidalguense una posición dominante que le permita otorgarse el lujo de desistir del apoyo de la universidad. Pues si bien es el líder de un grupo político, éste nunca alcanzó el poder estatal. Aún así, el control interno tiene un componente político estructural.

En lo que concierne al entorno, es muy fácil entender cómo un cacicazgo de esta naturaleza pudo constituirse y consolidarse en el contexto sociopolítico local del Estado de Hidalgo. Se debería poner atención al hecho de que haya podido prosperar en el escenario de las tentativas de modernización de la educación superior en México, pues la UAEH ha respondido con un empeño destacable a las directivas y programas federales sucesivos de

3 Ver "Universidad de Hidalgo, el cacicazgo de la Sosa Nostra", Proceso, 12 de marzo de 2007. 
esa modernización. En la propia institución, las lógicas burocráticas y clientelares se combinan y consolidan mutuamente, provocando una mayor e intensa enajenación respectiva. Así es como la retórica, basada en la fetichización de la UAEH como un elemento de modernidad y prosperidad en el Estado de Hidalgo, se articula con las viejas formas autoritarias, afectivo-obsesivas y clientelistas de poder. Con ello se subraya la estrecha solidaridad entre el entorno burocrático de la modernización de la educación superior en México, y las condiciones sociales de reproducción de ese cacicazgo.

\section{El capital universitario}

El capital por el cual se lucha dentro del campo de la UAEH es el capital universitario. Para entenderlo, se debe ubicar la ambivalencia del término "universitario" al interior de la institución. El adjetivo "universitario" remite primero al Grupo Universidad. "Ser universitario" implica lealtad con la institución y, por identificación implícita, con el grupo político que la controla. En este sentido, los "orgullosamente universitarios" son potencialmente todos los trabajadores (funcionarios, personal administrativo y personal académico) e integrantes (estudiantes) de la institución y hasta los ex-integrantes y simpatizantes que tienen y/o manifiestan un nexo real y/o afectivo con el grupo político y la propia institución.

Desde esta perspectiva, la definición de lo que es un sujeto "verdaderamente universitario" está en el centro de la batalla y, obviamente, se juega mucho con el doble y hasta triple referente de la palabra: el grupo político, la institución y la actividad universitaria, es decir, propiamente académica. Lo institucional implica y rebasa respectivamente al Grupo Universidad que se lo apropió y a la actividad universitaria que lo reivindica. La institución está bajo el control del grupo, cuyos integrantes se consideran los "verdaderos universitarios", pero para una parte importante de los académicos, de la población estudiantil y de los hidalguenses la universidad pertenece (o debería pertenecer) a la sociedad y al campo estricto de la investigación y de la educación.

No obstante, no se trata sólo de una batalla para la legitimidad universitaria como capital simbólico, sino de una lucha por la posesión del capital universitario real, es decir, por el control concreto de la institución. Cada uno trata de legitimar e imponer sus intereses para conservar o modificar la relación de fuerza. La lucha es tan desequilibrada que se olvida a veces que el poder universitario identificado con el Grupo Universidad le puede ser rebatido. Pero, si la institución parece pertenecer al grupo, los espacios de poder y de autonomía, así como recursos vinculados con ellos, siguen estando concretamente en lucha. De ambos lados - Grupo Universidad y académicos de profesión - existen otros intereses que rebasan las fronteras de la institución: intereses políticos para los primeros; carreras académicas para los segundos. En las condiciones actuales, muy desfavorables para los investigadores, la institución resulta ser a menudo un trampolín para carreras académicas que se prorrogan después hacia otros lados.

\section{La génesis}

Dentro de la universidad, el líder posee varios apelativos que deben ser a menudo acompañados de un cierto tono de voz para permitir identificar que se trata de él: el "licenciado", el "supremo", el "más allá" y "R1" siendo algunas de ellas. Sus cercanos colaboradores se refieren a él como a "un amigo".

Históricamente, es durante sus estudios de licenciatura cuando el líder logró acceder a la presidencia de la Federación de Estudiantes Universitarios de Hidalgo (FEUH) en 1977. En el contexto del auge del porrismo estudiantil en México, y en colusión con el gobierno del Estado de Hidalgo, la FEUH fue su base para tomar el control progresivo del Consejo Universitario y de la propia universidad. En ella, se formaron lealtades que, si bien conocieron varias rupturas y momentos de renovación generacional y estratégica, sobrevivieron 
parcialmente al período estudiantil de sus miembros. Hoy la sociedad de alumnos de la universidad sigue teniendo un papel en la estructura de poder de la universidad, si bien menor con relación al pasado. Es un espacio para el reclutamiento de futuros cuadros y un instrumento de penetración y presión de la población estudiantil tanto como de vigilancia e intimidación del profesorado.

La carrera del líder se focalizó después como Secretario General del Sindicato Único de Trabajadores al Servicio de los Poderes del Estado de Hidalgo (1980-1986) hasta que alcanzó la Secretaría General de la universidad (1986-1991) y se convirtió en Rector de la misma (1991-1998). En el transcurso, se había constituido el grupo político de la universidad al interior del PRI estatal. Este grupo nunca logró alcanzar una posición dominante dentro del partido y quedó excluido de los cargos del gobierno del Estado. Aún así, tuvo que ser tomado en cuenta en la distribución de las cuotas de poder. Es así como el líder fue propulsado a la diputación local (1981-1984) y federal (2000-2003 y 2006-2009). El objetivo era la gubernatura, pero después de dos veces como precandidato del PRI para la magistratura suprema del Estado (1998 y 2004), sus planes quedaron frustrados. Finalmente, se le concedió la presidencia del Comité Ejecutivo Estatal del PRI (2004-2006).

Al nivel de la universidad, ese proceso propició una ruptura hasta la fecha constitutiva del campo. Mientras la mayoría de las universidades estatales de México suelen estar subordinadas al gobierno del Estado, la UAEH logró autonomizarse del gobierno. Es así, de hecho, como se convirtió en cacicazgo y grupo político dentro del PRI estatal. La administración universitaria y el profesorado fueron progresivamente subordinados a los mecanismos de coerción y cooptación de ese poder caciquil. Para ello, este último se apoyó primero en complicidades políticas externas, logrando después ubicar sus elementos en los cargos estratégicos de la universidad y construir una red de intereses compartidos y de supervisión eficaz al interior de la institución.

Sin embargo, las exigencias federales de mejoramiento de los indicadores de calidad académica y la propia necesidad de canalizar recursos federales ante la hostilidad creciente del gobierno del Estado, impuso una política de mayor calidad académica. A pesar de la mala imagen del líder por su pasado porril, había que demostrar ante ella que el "proyecto universidad" era viable y portador de "progreso educativo y científico" con el fin de ganar legitimidad en la batalla política del Estado. Esto propició el estímulo a la formación de los cuadros académicos locales, así como la contratación de profesores e investigadores venidos de afuera, principalmente de otras partes de México y también del extranjero. La proximidad de Pachuca con la ciudad de México ayudó a esta política.

\section{La estructura de la lucha interna}

Las condiciones de esa génesis ayudan a ubicar y entender la estructuración de la lucha central del campo entre los que se encuentran vinculados con el Grupo Universidad y los que defienden las lógicas académicas en torno al capital universitario. Esta misma lucha se reproduce de cierto modo dentro de la población estudiantil. No se trata estrictamente de una lucha entre el Grupo Universidad y los académicos, ya que los académicos se encuentran vinculados con el Grupo Universidad. A la vez, no todos los que se encuentran vinculados con el Grupo Universidad son del grupo. Esta vinculación suele responder a lógicas internas que a veces pueden estar incluso en contradicción con intereses políticos externos. En cambio, se puede distinguir entre un polo académico, estructuralmente identificado con las lógicas e intereses académicos, y otro polo vinculado con el Grupo Universidad. Si bien existen puentes de uno a otro, tampoco cualquier forma de colaboración, incluso cercana, entre los dos polos permite plantear una vinculación. Ni tampoco una situación manifiesta de enemistad entre agentes del grupo y un sector académico indica necesariamente una mayor diferenciación estructural. Se trata precisamente de ubicar con precisión las condiciones 
estructurales de esa diferenciación y la manera cómo los distintos agentes se posicionan y los escenarios acontecen en medio de esas condiciones.

Ya con los agentes bien ubicados en sus polos respectivos, se podrá analizar cómo los del polo académico participan de distintas formas en su propia dominación y tratan, a la vez, de modificar la relación de fuerza. El polo académico está dominado por las mismas condiciones de inserción progresiva (y muchas veces pasajera) de sus agentes en un campo constituido por reglas que precedieron a esa inserción. La forma no elegida de cómo entran en el campo determina a menudo su trayectoria posterior en él. Aún así, el Grupo Universidad requiere de los académicos, así como ellos necesitan tener y conservar su trabajo; lo que abre márgenes de presión mutua y de acción para los propios académicos. Si bien no resulta difícil calificar el polo académico como tal, la calificación del polo vinculado al Grupo Universidad es más delicada. Pues los términos "universitario" e "institucional" responden a su apropiación y monopolización por el grupo; y el análisis sociológico debe precisamente deconstruirlos. Tampoco se le puede otorgar el privilegio de "poder universitario", ya que el otro polo define a su manera, por lo menos potencialmente, un poder. En este sentido, será apropiado destacar la naturaleza política del Grupo Universidad y llamarlo "político"; no porque todos sus agentes estén identificados con los intereses políticos del grupo, bien al contrario, pero porque están configurados internamente por la lógica política de ese polo.

Para poder analizar las lógicas internas del campo, es propicio iniciar con la clasificación de los tipos de capitales involucrados en sus luchas. El capital económico y la clase social tienen un papel periférico. La población universitaria, desde los estudiantes hasta los académicos dependientes de su salario, se ubica en la parte media-baja de la escala social, con variaciones menores. A excepción del director del ICSHu que extrae mayores beneficios de su posición, los que tienen un estatus social mayor lo deben a posiciones y condiciones externas poco determinantes en las dinámicas internas. El estatus puede explicar cierto sentimiento de revancha de parte de los administrativos que se encuentran aún más abajo de la escala social y que por su relación orgánica con el polo político se ven en la posibilidad de afectar de una manera u otra a un investigador; sobre todo cuando juzgan que su actitud es demasiado altanera. El campo académico implica jerarquizaciones sociales y funcionales a menudo solidarias y no necesariamente legítimas que pueden ser objeto pertinente de una crítica de conjunto. En el caso de la UAEH, las lógicas inducidas por el polo político desembocan en una suerte de inversión de las diferenciaciones funcionales legítimas, en detrimento del polo académico. El simple hecho de que un agente de limpieza pueda aceptar o no abrir la puerta de la oficina de un investigador que olvidó sus llaves es una prueba de la posición de subordinación de los investigadores. Sin embargo, la aceptación o no de la solicitud no es prerrogativa principal del agente y es señal de la posición que ocupa el investigador en la percepción de uno o varios agentes del polo político. Los administrativos, a menudo vueltos invisibles por la humildad de su labor, son los ojos del polo político.

Tampoco habría que creer en una superposición estricta entre las divisiones del campo político hidalguense y las batallas internas del campo de la UAEH, aunque el Grupo Universidad sea un actor político. El campo político estatal (y nacional) se caracteriza por mucho oportunismo y una reingeniería permanente entre las distintas camarillas políticas al interior de los partidos y entre los partidos. Esto imposibilita la configuración de una estructura estable de lucha política que pueda reflejarse mecánicamente en las relaciones externas e internas de la universidad. El Grupo Universidad tiene que acomodarse con la presencia en ésta de una mayoría silenciosa (estudiantes, trabajadores) poco solidaria con sus intereses políticos y hasta hostil a ellos. Obviamente la expresión de esa hostilidad debe ser prudente. Algunos militantes y cuadros (de segundo plano) de partidos y redes políticas que se oponen al Grupo Universidad en la arena política son profesores de la institución. Esos "elementos" están sometidos a una vigilancia constante y son tolerados, mientras no entren en conflicto directo con los intereses del grupo, ni representen una amenaza real. En 
algunas coyunturas (la elección a gobernadores del 2004), se busca apoyarse en ellos para ampliar la red de apoyo político del grupo. En otras coyunturas, se vuelven agentes portadores de una intolerable enemistad política y se busca marginarlos e incluso eliminarlos de la institución. En este sentido, la enemistad política puede efectivamente ser un factor de polarización interna entre un integrante de la universidad y el Grupo Universidad. Aún así, no deja de ser sólo un factor, cuyo peso depende también de las interrelaciones internas. Las posiciones dentro del campo de la UAEH no corresponden pues necesariamente con las posiciones políticas externas.

Bartra (2007) había advertido sobre el carácter raquítico de la crítica en las ciencias sociales en México:

\begin{abstract}
¿Qué es lo que inhibe la crítica? Podemos señalar varias causas inmediatas: influencia de caciquillos académicos que bloquean el trabajo de aquellos que no comparten sus intereses o ideas; presencia excesiva de un sector mediocre, estéril, burocratizado e indiferente a lo que se genera a su alrededor (...) efecto de potlatch igualador que bloquea el apoyo a quienes se considera que destacan excesivamente por encima del resto (síndrome de Liliput) (...) la exaltación desmesurada de alguna obra se debe a que su autor ejerce o ha ejercido poderosas funciones burocráticas o gubernamentales (...) la defensa de las glorias locales frente a la influencia de corrientes extranjeras.
\end{abstract}

Estas variables que menciona Bartra son muy características del ámbito que estamos analizando en el ICSHu. Nos interesa subrayar la variable local/foráneo de los académicos en el ICSHu y, muy en particular, de los investigadores con plaza. En el ICSHu los locales son obviamente los hidalguenses, aunque un hidalguense que haya tenido una larga estancia en universidades extranjeras sin haber estado vinculado previamente a la universidad es más bien percibido como un foráneo y, de hecho, suele solidarizarse con los foráneos. Esa distinción no se fundamenta sólo en consideraciones geográficas sino más bien en percepciones sociales. En principio, los foráneos son mexicanos de otras partes y extranjeros, quienes suelen unirse ante la animosidad local e incluso manifestar un desprecio abierto hacia el provincialismo de los hidalguenses, sobre todo cuando estos últimos no han tenido una producción científica relevante ni estancias académicas duraderas en el extranjero.

\title{
Capitales específicos y posiciones
}

La lucha está primordialmente estructurada por la distribución desigual de capitales específicos y jerarquizados, constitutivos de los agentes y del capital universitario en disputa. Esta distribución se asemeja a la distribución de Pareto en términos, no de una ley sino de una regla genérica que refleja los aspectos de la vida universitaria en la cual, dicho con una simpleza engañosa, "pocos tienen mucho y muchos tienen poco" en términos de valor y poder.

He identificado cinco capitales principales. El primero es la ubicación de los agentes en la "red universidad": la mayor o menor cercanía con el líder, su antigüedad y su calidad; así como los nexos formados al interior de la red (capital "red"). El segundo son los cargos burocráticos que se tienen y se han tenido en la institución o en espacios que la implican (capital burocrático). El tercero son las distintas formas burocráticas de reconocimiento de la formación y de la labor académica: títulos, reconocimientos, otros sistemas de incentivos y premios (capital burocrático-académico). El cuarto es el prestigio intelectual como tal, a través de publicaciones científicas, de la presencia mediática, de estudios en universidades notorias y del reconocimiento externo por redes académicas (capital intelectual). El último 
es el capital político, es decir, la presencia y posición de los actores en la arena política local y nacional.

El polo político se caracteriza por la posesión mayor de los dos primeros capitales y el polo académico por los dos siguientes. Esto no significa que no puedan tener acceso a los demás pues agentes del polo académico acceden a cargos medios (jefaturas de áreas académicas, coordinaciones de programas educativos) e incluso a direcciones generales (casi nunca a direcciones de institutos, ni a los puestos estelares de rector, secretario general y director de finanzas). Su posición varía en la "red universidad". Muchos agentes del polo político tienen un estatus académico y aplican en los programas de reconocimiento burocrático-académico, si bien no es siempre el caso, ni su prioridad. Hay que separar las expresiones estrictamente institucionales de los estatus de la realidad estructural de la ubicación de los actores en el campo. El capital político es más transversal. Numerosos agentes del polo político se encuentran, en este plano, en una situación de dependencia total con el líder del Grupo Universidad. Los que han logrado autonomizarse de él han acabado siendo marginados del grupo y de la universidad. Algunos agentes del polo académico tienen también intereses en la arena política local. Finalmente, cabe precisar que los capitales burocrático-académico e intelectual se encuentran en posición de dominados con relación a los dos primeros.

En su Homo Academicus, Bourdieu definió dos tipos de poder universitario respectivamente ligados con la posesión mayor del capital burocrático y del capital científico (Bourdieu 1984b). En este caso, el polo político privilegia la posición en la "red universidad" sobre la posesión del capital burocrático. Asimismo, el polo académico se mide más por indicadores burocráticos-académicos que por el prestigio intelectual, ya que éste se encuentra muy rarificado (si bien no inexistente) en la universidad. Obviamente esa situación incrementa la dependencia del polo académico con relación al polo político, porque existen medidas de castigo (restricción de apoyos para investigación, publicaciones y viajes a congresos) que contribuyen a debilitar los indicadores del académico castigado. Sin embargo, los académicos que cuentan con mayores redes externas y recursos intelectuales logran sustraerse mejor a esas medidas, encontrando más fácilmente otros canales de promoción para publicaciones y proyectos externos.

El polo político requiere de académicos que mejoren los indicadores de la institución, pero demasiado prestigio intelectual puede desembocar en una peligrosa autonomía para el control interno. Esa tensión se resuelve fatalmente en detrimento de la calidad científica. Un académico que tiene altos indicadores de publicación externa, pero no apoya a los "proyectos de la institución", es poco valorado y hasta combatido dentro de la universidad. La lógica clientelar y productivista inducida por los "proyectos de la institución", con la complicidad involuntaria de los programas federales, es un antídoto eficaz a la creatividad científica.

\section{El líder}

En base a los capitales definidos, resulta posible construir la tipología de los agentes del campo de la UAEH. En el polo político, el líder constituye una figura aparte que puede compararse al Gran Hermano omnisciente de George Orwell. El propio dispositivo de poder construido requería de esa figura, la cual no es generadora del dispositivo, sino parte del mismo. El líder tuvo disposiciones sociológicas que lo ubicaron en esa posición privilegiada.

El control se fundamenta tanto en mecanismos reales de supervisión a través de la red universidad como en el carácter invisible e imaginario de su omnisciencia. Los seguidores que dependen de él tienen interés en difundir ese imaginario, siendo, a la vez, enajenados 
por él, ya que quedan así subordinados a su arbitrariedad. La población universitaria que lo denuncia contribuye paradójicamente a reforzarlo, porque valida el imaginario de su omnisciencia y propaga sus consecuencias paranoides. Tanto adentro como afuera de la universidad, existe un sinnúmero de narraciones sobre las exacciones (reales e inventadas) del Grupo Universidad y de su líder, así como una inmensa fantasmagoría construida entorno a la naturaleza realmente gansteril del poder constituido dentro de la universidad. Esto se debe al propio carácter velado de las acciones, lógicas y relaciones ocultas detrás de sus manifestaciones visibles. En vez de ayudar a desestabilizarlo, esa producción discursiva alimenta su capacidad mistificadora y sacraliza la figura de su líder. En él se concentra el capital político de la red universidad que lo integra como su figura mayor. Los capitales político y burocrático acumulados consolidan su posición de dominante en la red.

\section{Los guardianes}

Los colaboradores cercanos del líder los denominaremos "guardianes". Ellos tienen también una posición dominante en la red, ya que forman parte del primer círculo - antiguo o regenerado - del líder. En consecuencia, gozan de posiciones burocráticas altas que se van rotando y logran a veces juntar un poco de capital burocrático-académico, pero en general disponen de poco capital académico e intelectual. Tampoco suelen estar políticamente muy bien ubicados, ya que son dependientes estructurales de un grupo que nunca alcanzó la realidad del poder en el Estado de Hidalgo, siendo el líder el único beneficiado real en la arena política.

En el caso de 1CSHu, el director entre 2005 y 2010 correspondía al prototipo del "guardián”. Fue promocionado a la secretaria general (segundo rango jerárquico) de la UAEH. En 2016 se convirtió en rector interino de la misma siendo ratificado en 2017 como nuevo rector electo. Egresado de la carrera de derecho de la universidad, como todos los directores del ICSHu, había sido un preponderante activista entre las filas estudiantiles del líder y contaba con una larga trayectoria en altos cargos de la institución.

\section{Los funcionarios}

Una franja de los altos funcionarios de la universidad no tienen vínculo estrecho con el Grupo Universidad. Los llamaremos los "funcionarios". Si bien se ligan con el polo político, al cual deben sus posiciones burocráticas, su papel responde principalmente a criterios funcionales o políticos. Se les aprecia por sus competencias administrativas o se busca en ellos algún tipo de respaldo político para el grupo, a pesar de que no les sean fieles. En el primer caso, son agentes más impersonales del polo político con grados variables de subordinación a él, pero dependientes de él, ya que su único capital radica en su posición burocrática. En el segundo caso, su presencia en la institución suele ser efímera, por lo que no la pueden ver de otro modo que como un botín, pues a menos que renuncien a cualquier tipo de autonomía y se vinculen al grupo político, no tienen un interés real en construir una relación duradera con la universidad.

Cabe mencionar que un guardián desleal al grupo se convierte en simple funcionario, antes de tener que renunciar a su cargo y muchas veces a la propia universidad. Los guardianes con mayor proyección se han quedado sistemáticamente detenidos en sus aspiraciones en la secretaria general, sin poder alcanzar la rectoría y terminaron renunciando para seguir su carrera política en el gobierno. Así como se puede salir de la condición de guardián, un funcionario que demuestre "compromiso con la institución" tiene la oportunidad de ganarse la confianza del líder e integrar su primer círculo, si bien éste sigue siendo celosamente reservado. 


\section{Los operadores}

El último grupo del polo político y sin duda el más necesario de todos, aunque de jerarquía menor, es él de los "operadores". Los operadores son los que, desde posiciones subalternas, vigilan, informan, movilizan y organizan a la población estudiantil y académica. Se trata principalmente de académicos y de funcionarios medios (con estatus académico o estatus de "personal de confianza"). La mayoría son locales, pero existen casos de conversión foránea. En el ICSHu los operadores están estratégicamente ubicados en las coordinaciones de las licenciaturas (pero no todos los coordinadores lo son), en la secretaria académica, así como en cargos de manejo presupuestal, de vinculación y de organización de los numerosos eventos protocolares y académicos del instituto, pues la supervisión de dichos eventos y de la población estudiantil, en general, son considerados como puntos esenciales y sensibles del control interno. Sin embargo, no se requiere tener un cargo para ser un operador, ya que la naturaleza de la operación es más informal que formal. Los otros operadores se ubican en el personal administrativo (secretarias, intendentes, agentes de limpieza) y entre los integrantes de la sociedad de alumnos. Los cuadros principales de esta última son efectivamente aspirantes a ser futuros guardianes.

Algunos operadores tienen el beneficio de una relación directa con el líder; otros la tienen con agentes centrales de la "red universidad". En todo caso, su poder depende casi exclusivamente de la conservación y del mejoramiento de su posición en la red. Obviamente su capital intelectual suele ser menor. Si lo han tenido algún día, lo van sacrificando a sus insaciables labores. Cuando tienen una plaza de investigador se les pide cuidar la parte de los indicadores burocrático-académicos. El capital burocrático de los operadores está totalmente sometido a la buena voluntad de los guardianes de los cuales dependen y a las configuraciones sucesivas de las relaciones de fuerza entre guardianes.

\section{Colaboradores y disidentes}

Existe una estricta diferenciación entre la figura académica del "colaborador" y la figura política del operador. La operación significa el sacrificio de la carrera académica. La colaboración se basa en su conservación y hasta en su promoción. La operación está al servicio del polo político. La colaboración se define por una tensión constitutiva con él. La operación es una forma de inserción en el campo o, cuando se ingresó como académico, el resultado progresivo de la socialización interna; pero se es operador ante cualquier otra cosa. La colaboración puede ser la condición no elegida de inserción en el campo o el resultado de una conquista, promoción o imposición; pero se es académico antes de ser colaborador. Este último realiza algunas de las operaciones del operador, pero en grado menor y sin agotarse en ellas. Si descuida su capital académico termina por encontrarse en una situación de vulnerabilidad y lo más probable es que se tenga que reubicar en el polo político.

El colaborador es un intermediario entre el polo político y el polo académico y cuyos intereses propios se ubican en el segundo. Por lo mismo, el colaborador oscila entre su papel de colaboración y su solidaridad fundamental con el polo académico, donde suele tener enemigos y amigos (tal como lo condiciona la propia inercia de las lógicas del campo). La dificultad inherente a su posición explica porque el colaborador termina casi siempre en contradicción con el polo político. Si va muy lejos en la colaboración, acaba beneficiándose de promociones de doble filo. Si desarrolla formas excesivas de resistencia (principalmente pasivas por obvias razones), lo regresan al rebaño de los académicos y, en caso de perjuicios, llegan incluso a cesarlo de la universidad.

Muy pocos académicos no han sido involucrados, en algún momento de su trayectoria universitaria, en fases de colaboración y/o de disidencia. La mayoría invisible es también la zona de repliegue de los colaboradores desclasados y de los disidentes aplacados, así como una fase posible de transición entre ambas posiciones pues las dos posiciones son intercam- 
biables. Cuando se colabora o se diside no se hacen fundamentalmente cosas distintas; salvo en el plano coercitivo, cuando la colaboración responde a un cargo de funcionario. Se trata principalmente de matices casi simétricamente inversos de posturas y estrategias internas de supervivencia académica, alimentados por la misma inconformidad y promoción de intereses. La colaboración implica una disposición (o resignación) a pactar y negociar (en situación de desventaja y de forma subrepticia) con el polo político, con el fin de obtener algunas ventajas de ello o por simple necesidad. Cuando se tiene un cargo, la colaboración consiste en supervisar, canalizar y discriminar la población académica a través de las prerrogativas específicas de los cargos asignados y de iniciativas apoyadas (o no) a nivel académico e institucional. En este sentido, la colaboración se asemeja a la operación, pero más en un espíritu de intermediación que de estricta instrumentalización de directivas. En todos los casos, la colaboración impone impulsar (no sólo atender) algunas demandas y metas académicas de la institución, por lo que define una forma de liderazgo académico subordinado a los intereses del polo dominante.

Sin embargo, la mayoría de los colaboradores privilegian sus intereses académicos individuales y coalicionados, colaborando únicamente en la medida de lo necesario y según esos mismos intereses. Su papel coercitivo termina generalmente sirviendo a esos intereses. Servir a la institución es servir a sus dueños; evitar servirla es servirse. Poco antes de renunciar a mi puesto, recuerdo que el Jefe de Área de Historia y Antropología del ICSHu arremetió contra lo que consideraba mi "falta de compromiso con la institución", lo cual a su vez disgustaba a la camarilla: “¡eres un aprovechado de la institución!”, exclamó. Este resulta ser un efecto funesto de la relación de fuerza del campo.

En cambio, la disidencia implica la expresión de una hostilidad más o menos abierta a la institución o a un sector de la institución, así como una resistencia más o menos firme a los proyectos impulsados por ellos. No se confunde con la oposición, ya que una actitud de oposición es insostenible, provocando forzosamente la salida de la institución. En cambio, suele ocurrir que un investigador empujado hacia la puerta de salida o brutalmente cesado exprese abiertamente su oposición. Si ha tenido una larga trayectoria universitaria, no cabe duda que sus estrategias internas fueron más ambivalentes. Los disidentes son como un espejo de los colaboradores. Mientras estos últimos pactan con el polo político, protegiendo espacios e intereses académicos, ellos rehúsan "apoyarlo", reclamando espacios académicos y cediendo en algunos aspectos. La conciliación no elimina la inconformidad y se acompaña de resistencia, pudiendo terminar en diferencias tangibles con el polo político; la hostilidad no es de total franqueza y se acompaña de concesiones y búsqueda de apoyos en la red. Las razones de la disidencia son variables y la heterogeneidad de los disidentes dificulta la cohesión entre ellos. Se es disidente porque se está inconforme con lógicas o personalidades de la institución o de un sector de la institución; porque se ha sido desplazado; porque se ha sufrido un agravio; por no sentirse lo suficientemente reconocido o por la inseguridad que genera un bajo perfil académico ante la presión institucional e incluso la de los pares. Hay un elemento bastante encubierto de oposición, extensible a la mayoría de los académicos por su posición de dominados, pero más manifiesto en la disidencia. Sin embargo, su concreción mayor suele deberse a circunstancias individuales e intereses, incluso políticos, no fundamentalmente motivados por lógicas distintas de las de la colaboración.

La polarización entre disidentes y colaboradores consolida la condición más decisiva de su dominación por el polo político: su división bajo fórmulas de coaliciones rivales y hasta de atomización. Todos recurren a estrategias conspirativas que los ubican claramente en las lógicas dominantes del campo. Existen también factores objetivos que explican esa división endémica. Los colaboradores suelen tener mayor capital académico-burocrático e intelectual que los otros académicos, ya que sin un plus cualitativo no serían interesantes para el polo político. Por ello, los foráneos son colaboradores predilectos (si bien, nada exclusivos), lo que incrementa la xenofobia y, por ende, la división. Su capital burocrático los ubica en 
puestos medios, en situación de total dependencia ante la voluntad del director. Pueden tener nexos en la "red universidad", siendo incluso asesores del líder, pero su posición en la red es bastante precaria.

Por ello, aún cuando la contemplación desdeñosa y pasiva de la realidad haya traído consecuencias nefastas, no existe una salida sencilla para el polo académico. La inconformidad de este polo suele ser heterogénea y hasta contradictoria en sus intereses secundarios; así como parcial en su entendimiento del tipo de lógicas con las cuales hay que romper, ya que todos se encuentran inmersos en ellas. Los disidentes no encuentran solidaridad en los colaboradores; los colaboradores no ven una opción viable de cambio en los disidentes; todos en un momento u otro juegan el juego de la institución en contra de sus potenciales aliados, intercambiando a veces posiciones y dedicándose a la polarización.

Además, el tiempo necesario para la asimilación crítica de las lógicas y la gran deserción académica no ayudan a conformar solidaridades duraderas. La ruptura potencial no radica pues en los disidentes, sino en la unificación política del polo académico y en la conformación de lógicas alternas. Siendo la toma de palabra como un "nosotros" impensable (aunque siempre en estado latente), cada uno juega su juego -quedando subordinado a las condiciones que todos imponen a todos- hasta la posibilidad de deslindarse definitivamente de la institución. Este acto de interrupción, este "gesto", es el acto anti-hegemónico por excelencia.

\section{Polo político y polo académico}

El polo político es un conjunto de posiciones muy diversas que, a través de distintos mecanismos tangibles y simbólicos de control, acaba teniendo una coherencia implacable. Si bien ésta no otorga el privilegio de la soberanía, confiere una posición dominante en el juego. En cambio, el polo académico está constituido por una comunidad relativamente homogénea de intereses primarios que se caracteriza por divisiones permanentes inducidas por las propias lógicas del campo. Para el polo político, se trata por supuesto de conservar el control efectivo de la institución y de poner a la masa académica al servicio de sus intereses políticos y burocrático-académicos. Esto implica que los académicos atiendan las funciones sustantivas de formación e investigación de la institución. Pues, tanto en el plano burocrático como académico y a pesar de las anomalías introducidas por las intromisiones recurrentes del poder informal, la universidad mantiene una funcionalidad aceptable.

Del lado del polo académico, la lucha consiste precisamente en defender la legitimidad y los derechos concretos de la actividad académica, canalizando recursos hacia ella y protegiendo sus espacios de autonomía. Ese polo se define por su interés fundamental en preservar su frontera con relación al polo político, negociando, a la vez, recursos que este último le pueda proporcionar. En las condiciones actuales de desequilibrio de la lucha, la estrategia es más bien defensiva. En términos estructurales, el polo académico tiene la propensión y vocación política de conquistar el monopolio del capital universitario. Si bien ambos polos lo reivindican como suyo, deben hacerse concesiones. El polo político lo tiene secuestrado, pero su sostenibilidad y dominación radica también en su capacidad para comprometer el polo académico en intercambios que no lo pueden dejar totalmente fuera de la repartición del capital. Al interior de las transacciones, los agentes del polo académico intentan consolidar sus posiciones y capitales específicos, participando así de su propia dominación.

En todo caso, la conciencia de la frontera que lo separa del polo político es fundamental para entender las lógicas y dinámicas del polo académico. El propio polo político tiene interés en mantener esa frontera. En caso contrario, se quedaría sin académicos. Su apuesta consiste más bien en tenerlos en la posición lo más subordinada posible, limitando al máximo su diferenciación estructural. Esto no significa que no existan puentes de un polo a otro. Agentes del polo académico acaban siendo operadores y hasta guardianes. Lo último ocurre raramente, sobre todo en el caso de académicos foráneos; los "guardianes de cuna" 
no abren tan fácilmente las puertas suspicazmente cerradas de su coto y, si bien hay muchos llamados a ello, los elegidos son pocos. Existen casos-límites de académicos con puestos de funcionarios que se ubican en las fronteras ambiguas de la operación y de la colaboración. No obstante, ese tipo de situaciones terminan por definirse de un lado u otro pues los compromisos que adquieren en cada polo son difícilmente compatibles: primero porque la ardua labor de la operación se combina muy mal con el trabajo académico; segundo porque los agentes del polo académico no simpatizan con el polo político. Entre ellos, es fácil discernir un sentimiento mayoritario de inconformidad con la institución, independientemente de las posiciones que tengan, lo cual no implica necesariamente solidaridad ni unidad estratégica.

\section{Conclusión}

Nos hemos referido a la UAEH en su descripción como una institución pública del Estado mexicano que dispone de un modelo normativo. Se trata de una entidad racional, centralizada y burocrática que, además de monopolizar la educación superior en el Estado de Hidalgo, se impone sobre la sociedad empleando constricciones y tomando decisiones, aparentemente de forma neutral y desinteresada. Sin embargo, este modelo no es real ya que, por un lado, la estructura de racionalidad y orden impuestos tiene consecuencias infaustas, y por otro, la política de la UAEH no refleja esta naturaleza desinteresada y racional. En efecto, la UAEH no representa sino un caso particular del feudalismo político que describe la situación de poder en la que gobernadores, caciques y caudillos locales imponen su voluntad al margen del gobierno federal. Ello explica por qué la UAEH constituye un caso paradigmático de cómo el sistema de camarillas se apropia de la universidad y alimenta fortalezas regionales de dominación patrimonial, cada vez más bunkerizadas, compuestas por pequeños grupos de personas que monopolizan el poder. Debido, en gran parte, a esta lenidad gubernamental la "red universidad" está persuadida, a la manera de Maquiavelo, de que es fuerte mientras el académico es débil. Así el académico puede ser fabricado y domesticado por los discursos de poder. En suma, objetivizado por la manera como se le trata.

Erradicar totalmente la resistencia en una organización es una misión imposible, tal como señalaba Weber. El juego institucional permite la discrepancia, pero no permite la salida de la discrepancia fuera de la delgada línea roja del sistema. Entrando a "jugar" es como se pierde el juego y salirse del juego acaba siendo la única forma, paradójica, de ganarlo. Podría ser mejor "cambiar el juego", pero es también un forma de jugarlo; dejar de jugarlo es renunciar a cambiarlo. La combinación del respeto absoluto de la formalidad y del carácter absolutamente informal del poder real es un rasgo central de la naturaleza del control ejercido al interior de la institución. En el ICSHu ocurre a menudo que un cierto número de personas interpretan un guión del cual cada una conoce todos los subterfugios y cuyos únicos espectadores son ellas mismas. El juego suena ridículo; es simple, pero no tiene nada de trivial. La ilusión teatral creada y la distancia aparente de la conciencia que se tiene de ella involucran a cada actor en su propia disciplinación, haciéndole creer que él no lo juega realmente, cuando lo está jugando; o que él lo juega mejor que los demás, cuando perdió ya conciencia de ser una simple pieza en la tabla de ajedrez. El genio del dispositivo radica en el simulacro, no en sus piezas: ni siquiera en la del rey.

\section{Bibliografía}

Bartra, R. (2007), "Las ciencias sociales en su tinta”, Nexos, 359, Noviembre, México D. F.

Bourdieu, P. (1984a), Questions de sociologie, Paris: Éditions de Minuit.

Bourdieu, P. (1984b), Homo academicus, Paris: Éditions de Minuit.

Bourdieu, P. (1992), Réponses. Pour une anthropologie réflexive, Paris: Le Seuil.

Foucault, M. (1986), Vigilar y castigar, Madrid: Siglo XXI Editores.

Foucault, M. (1997), Las palabras y las cosas, Madrid, Siglo XXI Editores. 
González Alcantud, J. A. (1997), El clientelismo político: perspectiva socioantropológica, Barcelona: Anthropos.

Herrera Cabañas, A. (1995), Política y gobierno en Hidalgo, México D. F.: Fundación Arturo Herrera Cabañas.

Lomnitz, C. (1995), Las salidas del laberinto: cultura e ideología en el espacio nacional mexicano, México D. F.: Planeta.

Lomnitz, C. (1996), "Ritual, rumor y corrupción en la formación del espacio nacional en Mexico", Revista Mexicana de Sociología, 58(2):21-51. México D. F.

Panster, W. G. (2008), “Construyendo un cacicazgo en una universidad neoliberal”. Traduccion por el Suntuap en marzo de 2008, artículo en línea disponible en www.suntuap.net / documentos / caciquismobuap.pdf, 22 de junio de 2014.

Reed-Danahay, D. (2001), “Autobiography, intimacy and ethnography”, In Paul Atkinson, Amanda Coffey, Sara Delamont, John Lofland, and Lyn Lofland, Edited by, Handbook of ethnography. p. 407-425.

Rivera Flores, A. (2004), La Sosa Nostra. Porrismo y gobierno coludidos en Hidalgo, México D. F.: Miguel Angel Porrúa.

Thompson, J. (1994), Organizaciones en acción, Bogotá: McGraw-Hill.

Weber, M. (1984), Economía y sociedad, México D. F.: Fondo de Cultura Económica. 